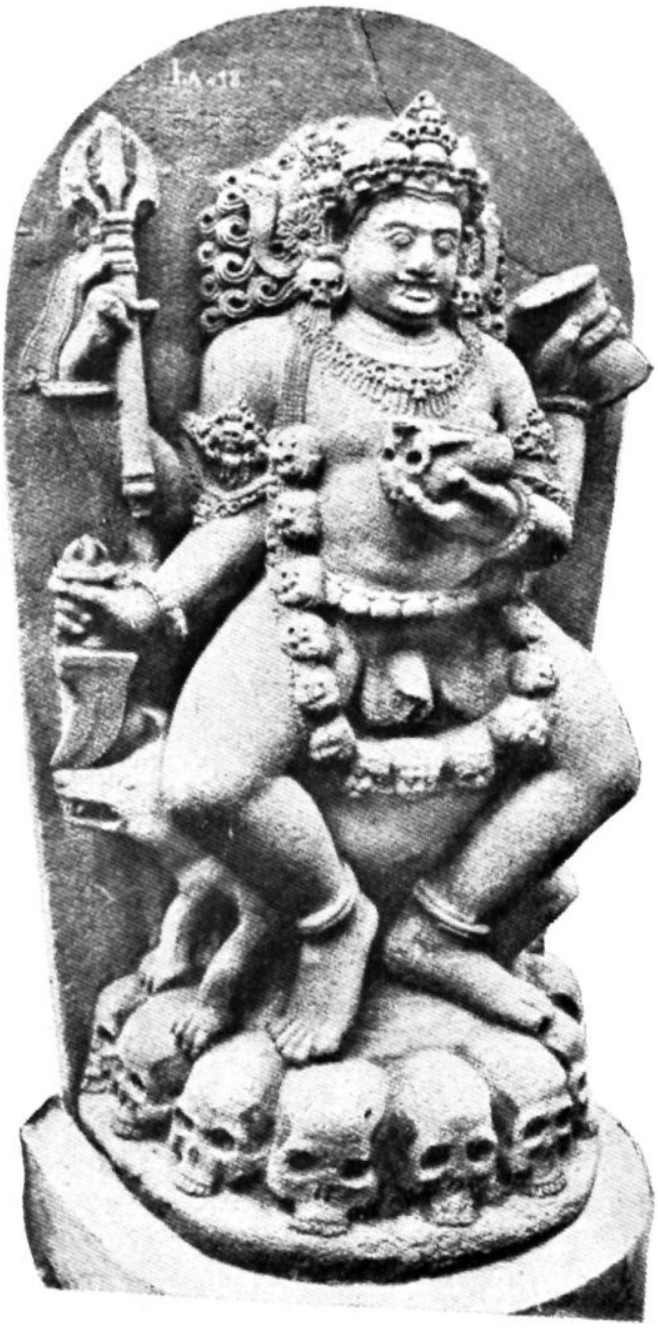

Portretbeeld van Kṛtawardhana (?) als Watuka Bhairawa.

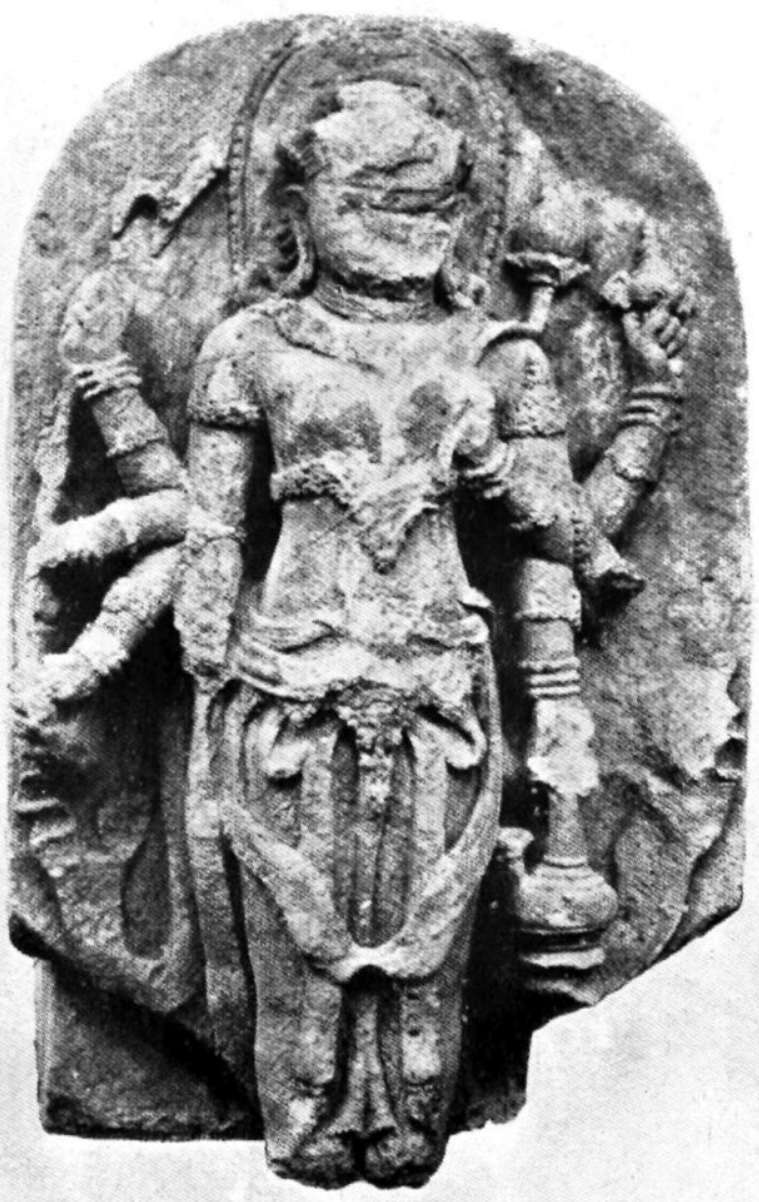

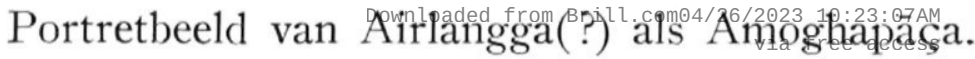
Koetri. Zuid-Bali. 


\title{
ENKELE OUDHEIDKUNDIGE OPMERKINGEN OVER HET TANTRISME OP JAVA.
}

\author{
DOOR
}

\author{
F. M. SCHNITGER.
}

1.

\section{Een buddhistisch beeld van Airlangga?}

Enkele jaren geleden vond Dr. W. F. Stutterheim in de desa Koetri op Bali een groep oude beelden. De interessantste daarvan waren een Durgā (waarschijnlijk een bijzettingsbeeld van Airlangga's moeder Mahendradattā) en een Amoghapāça ${ }^{1}$ ). Het laatste beeld meende de geleerde schrijver te moeten beschouwen als dat van Airlangga, of als dat van diens vader Udayana, of als dat van Airlangga's opvolger. Na eenig wikken en wegen, bleek hij aan den laatsten pretendent de voorkeur te schenken ${ }^{2}$ ).

Wij wagen het in alle bescheidenheid de juistheid dezer opvatting te betwijfelen. Immers, wat weten we van het geloof der beide laatste vorsten? Vrijwel niets. Airlangga daarentegen wordt met den naam Lokeçwara tot koning gewijd ${ }^{3}$ ), en van dezen god is Amoghapāça een verschijningsvorm. Een groote merkwaardigheid is, dat het Balische beeld een vlammenden slang als attribuut voert. Dit hangt wellicht samen met een passage uit Airlangga's beroemde inscriptie te Calcutta. Daarin wordt o.a. gezegd, dat de koning zijn vijanden bestreed ,gelijk een vlammende slang” " ).

Omstreeks 1250 en 1370 bloeide op Java en Sumatra, respectievelijk onder Wișnuwardhana en Addityawarman, een Amoghapāçacultus, waarin demonische godheden een voorname plaats innamen. Tjaṇdi Djago, de bijzettingstempel van den eersten vorst, bevatte beelden van den duivelschen Hayagrīwa en een met dolk en schedel uitgerusten god, die Akṣobhya in den kroon draagt. Aan A dityawarman wijdde Ir. J. L. Moens een van zijn fraaie studie's, waarin hij den bloeddorstig-religieuzen aard van dezen monarch uitvoerig be- 
schreef $^{5}$ ). Ook $\bar{A}$ dityawarman noemt zich een incarnatie van Lokeçwara ${ }^{6}$ ).

Amoghapāça nu heeft o.a. eigenschappen van Indra ${ }^{7}$ ). Is het toeval, dat zijn drie vorstelijke vereerders hun naam met dien laatsten god verbinden? Of hebben we hier met de gewone Indra-vergelijking van vorsten te doen? Hoe het zij, de overeenkomst is te aardig om niet even te vermelden. De moeder van Airlangga heet Mahendradattā, terwijl de Menangkabauwsche potentaat Kuliçadharawaṃça, Indra's geslacht, het zijne noemt ${ }^{8}$ ). Kort na Airlangga's bruiloft werd de hoofdstad, ,waar zoolang een vroolijkheid heerschte als in Indra's rijk", in asch gelegd $\left.{ }^{9}\right)$. De tweede strophe van de Calcuttainscriptie bevat een hulde aan Triwikrama (dus een demonischen god!), ,,voor wien Indra - er is eenige reden om aan te nemen, dat dit Airlangga zelf is -, zoo groot door ontelbare heldendaden, zich altijd in vereering buigt" ${ }^{10}$ ), terwijl men op de Sumatraansche inscriptie leest over ,zijn doorluchtige majesteit Udayādityawarman, geweldig van macht, een Indra onder de koningen" ${ }^{11}$ ). Tenslotte vergelijkt de Nāgarakṛtāgama $(41: 2)$ Wiṣnuwardhana's neef Narasinghamūrti met Indra. Of de naam van Airlangga's vader Udayana samenhangt met de tallooze udayana-stukken, waar de Sumatraan zijn naam mee smukt ${ }^{12}$ ), blijve buiten beschouwing.

Onwillekeurig dringt zich de vraag op: was Airlangga óók een aanbidder van demonische godheden? A priori lijkt dit, in verband met de andere Amoghapāça-koningen, niet onwaarschijnlijk. Bedenkt men voorts, dat zijn moeder zich als de incarnatie van een demonische godin beschouwde en hijzelf Triwikrama vereerde, dan stijgt de kans. Ten derde zou men bij een krijgszuchtig vorst als hij eigenlijk niet anders verwachten; de vlammende slang van het Balische beeld kan dit misschien nog eens onderstreepen. 's Konings Wiṣnu-beeld van Bĕlahan heeft weliswaar de vreedzame gedaante, doch zit op een ongewoon strijdlustigen garuḍa. Onze veronderstelling zou natuurlijk aan waarschijnlijkheid winnen, indien we onder Airlangga's voorouders reeds demonenaanbidders konden aanwijzen.

Bezien wij b.v. de gegevens betreffende zijn overgrootvader Lokapāla. Deze çiwaitisch-wisnuitische koning had als wij-priester een vereerder van Wairocana ${ }^{13}$ ); de koningin heet dus elders terecht ,de partij der buddhisten toegedaan”, zij is ,gelijk aan een zwaan, die bekoorlijk is door 't verblijf in 't reine meer Mānasa" 14). Professor Kern, de vertaler, kon niet over voldoende tantrische teksten beschikken om in deze woorden een benaming te. lezen van $\bar{A} d y a k a \bar{l} l \overline{\text {. }}$ 
I) tantra's zeggen n.1. ,As the swan lives in the celestial lake called Mānasa, so she lives in the minds (mānasa) of her devotees" ${ }^{15}$ ).

Vindt deze mededeeling wellicht van andere zijde bevestiging? Lokapāla's wijdingsnaam was o.a. Bhuwaneçwara $\left.{ }^{\mathbf{1 6}}\right)$. De vrouw van dien god behoort in Nepal tot de z.g. negen Durga ${ }^{\prime} s^{\mathbf{1 7}}$ ) en bezit bij de tantristen twee demonische openbaringsvormen. Men hoore: „Thou art Durgā, seated on a lion, holding in thy eight hands various kinds of dreadful weapons, and destroying the enemies of the immortals”. Ten tweede: „I remember again and again the dark primeval Devī swayed with passion, her beauteous face heated and moist with the sweat of amorous play, bearing a necklace of berries, and clad with leaves" ${ }^{18}$ ). Een Durgā op een leeuw lijkt voor een Javaansche vorstin wat vreemd. Liever wijzen we haar ,the dark Devī” toe, te meer omdat deze in de commentaren Mätangini heet, dezelfde demonische godin die Adityawarman op zijn Amoghapāça-inscriptie aanroept. ${ }^{19}$ )

Men zal, dunkt ons, moeilijk kunnen betwijfelen, dat hier bepaalde verbanden aan het licht komen. Welke deze precies zijn, is niet te zeggen. In elk geval heeft Wiṣnuwardhana geen splinternieuwen cultus ingesteld, maar een, die reeds eeuwen geleden had bestaan. Over de Indische Amoghapāça-vereering is uiterst weinig bekend. Wanneer we echter zien,dat in een bepaalden tijd Amoghapāça-sūtra's in het Chineesch worden vertaald, mogen we daaruit met eenige zekerheid concludeeren, dat $\mathrm{A}$. toen te Çrīwijaya (de geliefde pied-à-terre der Chin. buddhisten) bekend was en mogelijk vereering genoot. Deze periode valt tusschen 587 en $907^{20}$ ). Het is goed dit in 't oog te houden bij een studie van den oorsprong van dezen cultus in den Archipel.

Laten we eindigen met twee kleine opmerkingen. Waarom noemde Airlangga zich Bhatara Guru? ${ }^{21}$ ). Omdat de tantra's grootendeels berusten op de vereering van ,the supreme Guru, .... he who is beautiful like camphor, the jasmine-flower, or the autumnal moon, with his two hands granting blessing and dispelling fear.... bright like the rising sun", een vereering, die tenslotte zoo buitensporig wordt, dat Guru een plaats in gaat nemen boven alle goden ${ }^{22}$ ).

Op de Lawan-inscriptie uit Airlangga's tijd ${ }^{23}$ ) worden in regel 3, 10 en 11 de pañcamahābhūta aangeroepen, in regel 5 de mahābhūta. Wie zijn deze wezens? Volgens de tantra's ether, vuur, lucht, water en aarde, de vijf tattwa's, Brahma, Wiṣṇu, Rudra, Içāna en Sadāçiwa, vormend een troon voor Dewi ${ }^{24}$ ). 
2.

\section{Over Adityawarman.}

$\bar{A}$ dityawarman stamt uit het geslacht van Kuliçadhara, d.i. Indra. Kuliça is een ander woord voor wajra. Op Java vinden we Indra met den wajra aan den Çiwa-tempel te Prambanan afgebeeld. De çiwaitische naam Kuliçadhara is dus een equivalent van den buddhistischen Wajradhara, en wie de tantrische, in casu Javaansche neiging tot syncretisme kent, zal een verwantschap tusschen beide goden niet ongerijmd achten. Men hoeft dus slechts aan te toonen, dat deze veronderstelling niet alleen voor den naam, maar ook voor het wezen geldt.

$\mathrm{Nu}$ beschouwt Adityawarman, de zoon van Kuliçadhara, zich als een incarnatie van Gagaṇagañja, die tot spiritueelen vader Akṣobhya heeft ${ }^{25}$ ). Merkwaardig genoeg is bij bepaalde tantrische secten Wajradhara een epitheton van Akșobhya ${ }^{26}$ ); de Balische Nāgabāyusūtra en Buddhakalpa noemen Wajradhara als een van de vier bodhisattva's, die dien dhyāni-buddha dienend omgeven ${ }^{2 \pi}$ ). Mocht men in onze redeneering eenige waarschijnlijkheid vinden, dan wordt de gissing, dat de bekende Akṣobhya van Barabuḍur, het heiligdom der wajradhara's, niet in de hoofdstupa gestaan zou hebben, onhoudbaar.

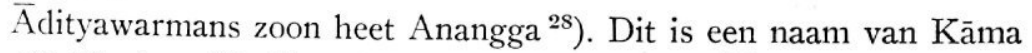
en Mañjughoșa ${ }^{29}$ ). Kan dit verwondering baren? A Aityawarman zelf hield zich, zooals Moens reeds aantoonde ${ }^{30}$ ), voor een incarnatie van dien eersten god, richtte in 1343 het beroemde Mañjuçrī-beeld van Djago op, en had, zooals gezegd, Akṣobhya tot geestelijken vader. Het spreekt bijna vanzelf, dat ook de god Anangga Akșobhya in de haartooi draagt.

3.

\section{Het Cakracakra-beeld van Singasari.}

Zooals men weet, bevindt zich onder de Singasarische beelden te Leiden een vierarmige, dansende god, die in de voorhanden schedel en dolk, in de achterhanden drietand en trom houdt. Het is Cakracakra, een bloeddorstige bhairawa, wiens naam elders nog niet werd aangetroffen. Reeds de eerste beschrijvers hebben aan dezen demon een buddhistisch karakter toegekend, en in de laatste studie van Moens ${ }^{31}$ ) is deze theorie nog eens naar voren geschoven. Er schijnt dus weinig twijfel dienaangaande te zijn. 
Wie de geloofsbrieven van dit beeld echter nader beschouwt, vraagt zich af, waar het overtuigend bewijs dezer hypothese eigenlijk op steunt. Immers, stylistisch is er aan dit beeld niets te bekennen wat zelfs maar naar buddhisme zweemt. Toen wij te Leiden het stuk bekend, viel onzen blik op een knopje, dat elke oorring bekroont; bij nader onderzoek bleek dit een lingga te zijn ${ }^{32}$ ), zooals vaak op den rozenkrans wordt aangetroffen. $\mathrm{Nu}$ bestaan inderdaad buddhistische lingga's, maar op Java zijn ze nog niet gevonden.

Bedenkt men bovendien, dat de Cakracakra in den zuiver Çiwaïtischen torentempel gestaan heeft, en in diezelfde gedaante met Ganeça een Pārwatī ${ }^{33}$ ) en een „Guhyeçwarī”-beeld ${ }^{34}$ ) te Singasari flankeert, dan kan er weinig twijfel bestaan dat het beeld niet buddhistisch, maar zuiver sizuaitisch is ${ }^{45}$ ).

Over de dateering ervan laat zich weinig zeggen. Met de Pārwati en „Guhyeçwarī" staat het in een nauw verband, en men zou gaarne aannemen, dat deze stukken uit denzelfden tijd stamden. Hier is natuurlijk geen bewijs voor, maar in elk geval zal een onderzoek naar de laatste beelden de dateering van het eerste makkelijker maken.

De „Guhyeçwari”” dankt haar naam aan Dr. Bosch. Maar G. is een buddhistische godin, en het Singasarische beeld is pur sang çiwaitisch. We zullen het dus, in afwachting van beter, Durgā noemen. Welnu, dit beeld werd in 1332 opgericht en kan dus een portretbeeld zijn van Tribhuwanottungadewī, Ayam Wuruk's energieke moeder.

Het Pārwatī-beeld sluit zich door den vorm van het potje, waar de lotusstengel uit te voorschijn schiet, bij het Singasarische Trnawindu-beeld aan, dat uit 1351 stamt $^{35}$ ); en door den kala-kop op de buikplaat bij de Panataran-rākṣasa's van $\left.1347^{35 a}\right)$. Op deze gronden zijn wij er niet heel zeker van, dat het Cakracakra-beeld van den torentempel uit Krtanagara's tijd stamt. De letters van de achterplaat hoeven niet naar Djago te wijzen, doch kunnen dat even goed naar Trnawindu doen. Men zou misschien geneigd zijn het beeld aan Tribhuwana's echtgenoot Krtawardhana toe te wijzen.

Blijven wij echter bij de feiten. Natuurlijk zou het even een verrassing zijn om Tribhuwana in demonische gestalte te zien uitgebeeld, terwijl de naam Bhuwaneçwara van haar zoon aan Airlangga's bhairawa(?) voorvader herinnert. Bovendien heet zij in zang 2 van de Nāgarakṛtāgama Tribhuwanawijaya, hetgeen een andere schrijfwijze is voor Trailokyawijaya, den naam van een, ook op Java ver- 
eerden, buddhistischen demon. Een nieuwsgierige gaat nu zoeken of het in deze buurt niet méér naar satan riekt.

Vooreerst is er Krttawardhana's epitheton Cakreçwara ${ }^{36}$ ). Een cakreçwara is de leider van een tantrische cakra-ritus, waar bloed, wijn en vrouwen een belangrijke rol in vervullen. Moens heeft daar in ander verband over geschreven, en er op gewezen, dat Krtanagara in deze practijken ver gevorderd was ${ }^{37}$ ). Cakreçwara zou dus een passende echtgenoot voor Durgā, alias Tribhuwana zijn geweest.

Volgens de Nāgarakṛtāgama (zang 3) bestuurde Cakreçwara gelijk Ratnasambhawa het land. Met deze mededeeling klopt oogenschijnlijk niet 's konings benaming Cakradhara, die toekomt aan Wairocana ${ }^{38}$ ). Toch hoeft men dit niet ongerijmd te vinden; de Akșobhya-vorst Krtanagara noemt zich immers eveneens een incarnatie van $W$ airocana $\left.^{39}\right)$.

Wanneer men zich bij deze voorstelling van zaken aansluit, blijkt wel hoe nauw de godsdiensten van Kṛtanagara en Krtawardhana samenhangen, hoe de verschillen meer de nuance dan het wezen raken, hoe het psychologisch onmogelijk is het beroemde Cakracakrabeeld aan een van beiden toe te schrijven. Ook al mocht dit later gebeuren, dan zal daarmee geenszins ontkend kunnen worden, dat beíde koningen in hetzélfde beeld hun diepste godsdienstige gevoelens bevredigd vonden ${ }^{40}$ ). Dat juist Akṣobhya en Ratnasambhawa zulk een gewichtige plaats in gaan nemen, schijnt niet toevallig. Volgens de Sanghyang Kamahāyānikan ontsproten ze uit Awalokiteçwara, den populairsten bodhisattwa op Java ${ }^{41}$ ).

Volgens de meening van Ir. Moens zou de Cakracakra geen portretbeeld, maar een dharmapāla, een bewaker van 's konings ,portret” in lingga-gedaante $z_{i j n}{ }^{42}$ ). Deze opvatting is in vele opzichten aanlokkelijk; toch zouden we op een andere mogelijkheid willen wijzen, overigens evenzeer hypothese.

Heeft er in den torentempel een lingga gestaan? Afgaande op de klcinc Midden-Javaansche heiligdommen, de vele, rijk bewerkte lingga's, die op Oost-Java gevonden zijn, en het feit, dat de linggacultus daar stellig een groote rol vervulde ${ }^{43}$ ), zou men de vraag bevestigend beantwoorden. Daar tegenover staat, dat in geen enkele groote Oost-Javaansche tempel lingga's staan; zouden deze er heusch alle uit weggehaald zijn? Het is mogelijk, maar niet bewezen.

Daarmee vervalt vanzelf de vraag of soms lingga's met beelden in de cella hebben gestaan. Op Midden-Java blijkt van een dergelijke 
gewoonte niet. Kan men zich nu b.v. in de kleine kamer van tjaṇdi Kidal, voor het vrij kleine beeld van Anūșapati een forschen lingga denken? Zou dat esthetisch wel bevredigd hebben?

Dit in aanmerking genomen, achten we het wat onwaarschijnlijk (zekerheid is er niet), dat de Cakracakra als dharmapāla heeft gefungeerd. De meest bevredigende oplossing lijkt, dat het wel degelijk een doodenbeeld was, en als eenige in de cella stond. Wil men deze gissing verwerpen, dan is er nog een middenweg. In ZuidIndië lieten vele koningen zich als dharmapāla vereeuwigen $\left.{ }^{44}\right)$. De Cakracakra zou dan een doodenbeeld voorstellen als bewaker van het godenbecld in lingga-vorm.

4.

Een tantrisch portretbeeld.

In deel 89 van deze Bijdragen (blz. 251 en 252 met foto) schreven wij over een Wiṣnu-beeld van Singasari. Dr. Bernet Kempers wees ons sedert op een interessante bijzonderheid, n.1. drie lingga's: aan de voeten, voor het middel, en in den kroon van het beeld. Hij vond o.a. daarin aanleiding van een çizwa-wiṣnuitische figuur te spreken ${ }^{46}$ ). Eenige twijfel aan die meening lijkt gewettigd.

De mystieke leer der tantra's zegt, dat het menschelijk lichaam drie esoterische centra van bewustzijn heeft, elk vertegenwoordigd door een lingga ${ }^{47}$ ). De benedenste, Swayambhū, bevindt zich vlak onder de genitaliën, de tweede, Bāna, in het hart ${ }^{48}$ ), de derde, Itara, tusschen de wenkbrauwen.

Mocht er tusschen deze en de Singasarische lingga's verband bestaan, dan heeft de Javaansche beeldhouwer ze waarschijnlijk uit esthetische overwegingen anders geplaatst dan de voorschriften zeiden. Onmogelijk kon hij er een tusschen de wenkbrauwen plaatsen; midden op de borst zou slechts een zeer kleine passen; op de derde plaats dito. De vrome vereerder had natuurlijk behoefte aan een duidelijke uitbeelding, want door concentratie moest hij zich vereenigen met de çakti in elken lingga, om ten slotte in den hoogsten op te gaan in Paramaçiwa zelf. Hij ,pierces the three lingga's", aanschouwt de dewī ,who shines therein in the fulness of her lustre", gaat met haar omhoog, ,lustrous like lightning and fine like the lotus fibre”, en ,goes to the flame-like Shiva”, die ,sudden produces the bliss of liberation".

Of wij deze beteekenis aan de lingga's van het Singasarische 
Wișnu-beeld mogen toekennen, blijft een open vraag. Wil men haar bevestigend beantwoorden, dan dient van de kwalificatie ,ک̧iz' $a$ wișnuitisch" te worden afgezien, daar de lingga's in dat geval niets met Çiwa te maken zouden heben, als zijnde gemeengoed van alle tantrische secten.

Den Haag, Maart 1933.

\section{NOTEN.}

1) Oudheden van Bali, bl. 126-134 en plaat 27, 29 en 30. Het Durgā-beeld op plaat 28 zou een portret van Çrī Wijayamahādewi kunnen zịjn, daar deze naam in de tantra's herhaldelijk als epitheton van Durgā geldt. Zie b.v. Avalon, Hymns to the goddess, bl. 147.

2) B1. 192.

3) Prof. Krom, H. J. Gesch. bl. 243.

4) Prof. Kern, Verspr. Geschr. VII, bl. 95.

5) T. Bat. Gen. 64.

6) Krom, bl. 413.

т) Moens, bl. 538 .

s) Krom, bl. 413.

9) Kern, bl. 93 .

10) Kern, bl. 92; ook Lokapāla kent dien demonischen god, Kern, bl. 22.

11) Kern, bl. 172 .

12) B. v. Kern, bl. 175.

13) Kern, bl. 22.

14) Kern, bl. 92.

15) Avalon, Hymns to the goddess, bl. 57.

16) Kern, bl. 21. Ayam Wuruk noemt zich in een van zijn inscriptie's Çuddhabhuwaneçwara. (Pararaton, $1^{\circ}$ ed. b1. 121).

17) Lévi, Le Népal I, bl. 377.

18) Avalon, bl. 37.

19) Moens, bl. 561 .

20) Zie Eitel, Handbook of Chinese Buddhism, onder Amoghapāça.

21) Krom, bl. 270 en 296.

22) Avalon, Principles of Tantra II, bl. 54-131. Guru kan ook demonisch zijn; ,the servants in his house are bhairavas and bhairavīs" (bl. 62).

23) Volgens Krom, b1. 270. De inscriptie zelf vindt men in Verh. Bat. Gen. 60, bl. 247. Vgl. bl. 162, regel 3 v.o., b1. 171, regel 15 en Goris in zijn dissertatie op bl. 67,98 en 149 .

24) Avalon, b1. 365 en 390 .

25) Moens, bl. 568.

26) Bhattacharya, Sādhanamālā II (1928), bl. IX.

27) Dr. Bosch in Med. Kon. Ak. v. W. afd. letterk. deel 68, serie b, no. 3. b1. 56 .

28) Krom, bl. 415.

29) Foucher, Ic. boud. II, bl. 46.

30) B1. 560. Vgl. Kern, Verspr. Geschr. VI, bl. 272.

31) Bl. 551. 
32) Op plaat 52 van de Singasari-monographie is het rechter exemplaar met eenige moeite te zien.

33) Zie plaat 74 van de S. monographie en een beschrijving bij Krom, Inl.

t. d. H. J. kunst II, bl. 87.

34) Foto's en beschrijving in Rapp. Oudh. Dienst 1929.

35) Plaat 79 v. d. S. monographie.

$3^{\mathrm{a}}$ ) Het demonenbeeld v. Djago (Krom, H. J. K. II, bl. 130) laten we buiten beschouwing, aangezien niets bewijst, dat dit beeld uit 1268 stamt.

36) Krom, H. J. Gesch., bl. 384.

37) B1. 532. Vg1. Avalon, Shakti and Shākta (1929), bl. 573.

Niet genoeg kan de nadruk er op gelegd worden, hoe door en door demonischtantrisch deze tijd was. Tegenover de kleinste bijzonderheden moeten wij wantrouwend staan. Twee voorbeelden.

Bekend is uit die dagen het keurkorps der Bhayankãri's (Krom, bl. 324). Dit woord zal waarschijnlijk in verband staan met Bhayankara, den naam van een Zuid-Indischen bhairazia (Avalon, Mahanirwānatantra, bl. 120).

Kṛtanagara's hofkapelaan Bhāskara (een naam van Sürya), die zoo trouwhartig aan Çiwāgni offerde (Krom, bl. 330), droeg den titel çankadhara, d.i. drager van de schelp. Men zij tegenover dit heerschap wat gereserveerd, want çanka is in de tantra's een euphemisme voor offerschaal, die gemaakt is uit een menschelijken schedel (Avalon, bl. 254).

38) Bhattacharya, bl. IX.

39) Krom, bl. 344.

40) Ratnasambhawa's demonische gedaante vindt men bij Bhattacharya, Buddhist Iconography, plaat XXVI d afgebeeld en op bl. 115 beschreven. Dansend op een lijk, een van bloed rookenden halven schedel in de hand, met opgerichten phallus, is de gelijkenis met Cakreçwara onmiskenbaar. De Balische Buddhakalpa (Bosch, 1.c. bl. 50) geeft R. als embleem den schedelnap.

41) Reeds in Indië moet deze ongewoon nauwe relatie tusschen beide ('hyãni-buddha's hebben bestaan. Vgl. Bhattacharya, bl. 114 en 115.

42) B1. 551.

43) Vg1. Krom, bl. 400.

44) Aravanmuthan, South Indian Portraits, bl. 28. Ons vermoeden, dat oudtijds Singasari de beelden van een dynastisch pantheon bevatte (Bijdr. Kon. Inst. 89, bl. 252), wordt door het voorkomen van dezelfde gewoonte in Zuid-Indië versterkt. „At Madura”, heet het op bl. 5, ,we have a hall in which statues of live generations of the Nayaka kings of that place are ranged in the order of succession. Fimilar galleries of statues are to be found in other temples". Volgt een reeks voorbeelden.

${ }^{45}$ ) Hier moet nog gewezen worden op een misverstand, n.l. de opvatting van de wajra als specifiek buddhistisch. Zoo schrijft Dr. Stutterheim over de wajravormige knots van Kṛtanagara's portretbeeld in Harihara-Ardhanāreçwarīgedaante (T. Bat. Gen. 72, bl. 726): „Deze wajra is eigenlijk het eenig uitgesproken buddhistische aan het beeld". Slip of the pen. Er is geen sprake van, dat de wajra specifiek buddhistisch zou zijn, en het door Dr. S. beschreven beeld vertoont evenmin buddhistische sporen als de Cakracakra met den wajravormigen drietand. Deze laatste komt ook voor bij den Nandiçwara van den torentempel, en bij andere çiwaitische beelden.

46) Zie stelling 5 van zijn proefschrift.

47) Avalon, The Serpent Power (1931), bl. 459, 460 en elders. Uit dit boek leert men menige bijzonderheid, die voor de studie van de Sanghyang Kamahāyānikan van belang kan zijn. Zoo verkondigt dit laatste geschrift, dat in het menschelijk lichaam een wajra rechtop staat. Dit moet rechtstreeks uit çiwai- 
tische bronnen geput zijn, daar deze eveneens die opvatting huldigen (Avalon, bl. $320,340,354,357$, enz.). Plaatst de S. H. K. den lichaamloozen Bhatāra Buddha in het stūpa-hoofd, de çiwaïtische geschriften denken zich Içwara eveneens in het hoofd (Avalon, bl. 433, 434 en 478), dat in dit geval de top van den lingga is en den naam nirālamba-puri, ,house without support" draagt. De drie concentrische cirkels der hoogste wijsheid, Içwara, Hiranyagarbha en Wirāt (teekening en beschrijving bij Avalon, The Garland of Letters, 1922, bl. 27) doen aan het bovendeel van Barabuḍur denken.

48) N.1. in de Anāhata-lotus. Aldaar groeit ook de hemelsche boom, die niet alleen alle wenschen vervult, maar tot verlossing (mokșa) leidt. Avalon, The Serpent Power, bl. 369.

\section{$\mathrm{N}$ a w o ord.}

$\mathrm{Na}$ Dr. Stutterheim van mijn vermoeden betreffende Airlangga's portretbeeld op de hoogte te hebben gesteld, schreef deze geleerde mij op 12 Sept. 1933 uit Jogja, dat hij onafhankelijk van mij tot dezelfde conclusie gekomen was.

Inmiddels is in afl. 2 van het T. B. G. 1933 een belangwekkende controverse over Krtanagara's portretbeeld te Berlijn ontstaan, die een geschikte aanleiding vormt om nog enkele détails van dit beeld te bespreken.

De Heer van Erp vestigde mijn aandacht op de insnoering van het voetstuk, die op Midden-Java niet voorkomt. Vermoedelijk is deze dus voor Oost-Java kenmerkend; ik wijs nog op het portretbeeld van Anūsapati en het schoone godenpaar van Poendjoel (Krom, Inl. III, pl. 94). Telkens is de versiering anders: nu eens een parelrand, dan weer een aaneengesloten bloemsnoer of losse, rozet-achtige ornamentjes. Mogelijk heeft men er buitenlandschen (Indischen?) invloed in te zien, want ook andere landen kennen deze ontwikkeling, b.v. China. Vgl. Fuhrmann's boek, pl. 50.

Al zijn ook de makara's als oor-versiering uit Indië afkomstig, toch hebben zij op Java vermoedelijk een bijzondere beteekenis gekregen. Oorsieraden spelen in de Javaansche verhalen een geheimzinnige rol (vgl. Kats, Wajang Poerwa, bl. 261); in de coiffure van Krttanagara symboliseeren ze mogelijk de beide rijkshelften. Vgl. Rassers, Pandji Roman, bl. 283 en 57, waar het land Daha door een olifant vertegenwoordigd wordt.

Wie de beelden van Aṇussapati en Kṛtanagara uit eigen aanschouwing kent, weet, dat ze in grootte en uitvoering zeer dicht bij elkaar staan. Daarnaast ontwikkelt zich een groep doodenbeelden van grooter 
formaat, die o.a. door de statue's van Wiṣnuwardhana en Kṛtarājasa worden vertegenwoordigd, terwijl een derde groep van kleinere beelden (b.v. die in M. v. B. Kunsten, 11e jrg., bl. 51 gereproduceerd: Çiwa-beeld te Berlijn) den stralenkrans als kenmerk draagt.

Deze drie, niet altijd scherp gescheiden groepen van één kunstrichting groeien naast - en niet na - elkaar op en oefenen wederkeerig invloed op elkaar uit; waarschijnlijk zijn zij plaatselijke variatie's van één school, die, via den Wiṣnu van Bĕlahan, uit de Midden-Javaansche is gegroeid en te Soekoeh en Tjĕta eindigt.

Een eigenaardige Indonesische nuance toonen het Jav. godinnebeeld van foto O. D. 7228 en de Balische ruiterbeeldjes van foto's 9319 en 9320. Deze staan immers op één lijn met de Battaksche ruiterfiguurtjes, dooden voorstellend, die naar het zielenland rijden.

Het beeld in het M. v. B. K. draagt een lingga in de hand, en wijst dus naar Zuid-Indië, waar men de gestorvenen eveneens een gouden lingga in de linker hand meegaf. Vgl. Thurston, Ethn. notes in S. I., p. 139; cf. p. 137; lingga op het hoofd, evenals in Kamboja.... en Java, zooals in 4 werd aangetoond.

Dat juist de linker hand gekozen werd, houdt misschien verband met de meditatie der attributen, waarbij men met de rechter beneden hand begint, en in gedachten een cirkel om het godenhoofd beschrijft. In de Javaansche geschriften worden de vier toestanden, waarin de jiwātman verkeeren kan, en de daarmee evenwijdig loopende trappen van dhyāna aan de armen van een god gelijk gesteld, n.1.: de staat van wakker zijn, de staat van droomen, de vaste slaap waarin geen droomen meer voorkomen, en die mystieke vierde staat (turīya). waarin men met den paramātman vereenigd, en toch niet zonder hewustzijn is. Vgl. Speyer in Bijdr. 1908, bl. 410.

In de linker hand werd de geloovige verlost in den lingga van zijn opperheer. Toch was dit blijkbaar niet overal het geval, daar, zooals wij zagen, de lingga ook wel op het hoofd werd geplaatst. Men krijgt eerder den indruk dat de geloovige in elke hand zijn laatste status aanschouwen kon, zoowel in de rechter beneden hand met den opgeheven lingga-wijsvinger (Harihara van Simping) of ākāçaduim (Çiwa van Kiḍal) als ook in de beide bovenhanden, die ,het binnenste van het hart" vasthouden. Vgl. Bijdr. 72, bl. 403.

Ligt het woord ,turīya” soms opgesloten in „Turyantapada”, den naam v. d. plaats waar Mpu Palot, Ken Aroks groote leermeester, vandaan kwam? Zie Par. $1^{\circ}$ ed. bl. 42. 
